\title{
A Review on the Cosmeceutical and External Applications of Nigella sativa
}

\author{
Ahmad M. Eid, ${ }^{1}$ Nagib A. Elmarzugi, ${ }^{2}$ Laila M. Abu Ayyash, ${ }^{1}$ \\ Maher N. Sawafta, ${ }^{1}$ and Hadeel I. Daana ${ }^{1}$ \\ ${ }^{1}$ Department of Pharmacy, Faculty of Medicine and Health Sciences, An-Najah National University, Nablus, State of Palestine \\ ${ }^{2}$ Department of Industrial Pharmacy, Faculty of Pharmacy, Tripoli University \& National Nanotechnology Project, Biotechnology \\ Research Center, Tripoli, Libya \\ Correspondence should be addressed to Ahmad M. Eid; ahmadeid@najah.edu
}

Received 3 August 2017; Revised 15 October 2017; Accepted 5 November 2017; Published 22 November 2017

Academic Editor: Marcel Tanner

Copyright (C) 2017 Ahmad M. Eid et al. This is an open access article distributed under the Creative Commons Attribution License, which permits unrestricted use, distribution, and reproduction in any medium, provided the original work is properly cited.

\begin{abstract}
It is estimated by the World Health Organization (WHO) that most of the world's population depends on herbal medicine for their health care. Nigella sativa (N. sativa), also known as black-caraway and as "Kalonji," is a well-known seed all over the world. It is one of the most common medicinal plants worldwide and contains many useful chemical constituents that we can find in its fixed oil, such as thymoquinone, thymohydroquinone, dithymoquinone, thymol, nigellicine, carvacrol, nigellimine, nigellicine, nigellidine, and alpha-hederin. Due to these numerous important ingredients it was found that it affects different areas of our body and has many pharmacological effects as antibacterial, antiviral, anti-inflammatory, and wound healing effect and also for acne vulgaris, skin cancer, pigmentation, and many cosmeceutical applications. Based on the folklore usage of $N$. sativa seeds and oil, they are used in various systems of food and medicines. The aim of this article is to provide a detailed survey of the literature of cosmeceutical and external applications of $N$. sativa which is expected to stimulate further studies on this subject.
\end{abstract}

\section{Introduction}

Nigella sativa, which is a member of the Ranunculaceae family [1], can be found all over the world but grows mainly in Eastern Europe, Middle East, and Western Asia [2]. It is a small shrub with tapering green leaves and rosaceous white and purplish flowers. Its fruit contains tiny dark black in color seeds [3] (Figure 1).

The seeds, which have two kinds of oil, fixed and essentials [4], also contain other things such as proteins, alkaloids, and saponins $[5,6]$. Much of the biological activity of the seeds has been shown due to the presence of thymoquinone [7], which is the major component of the essential oil but also present in the fixed oil. They have a very low degree of toxicity [8]. Only two patients of contact dermatitis have been reported after topical use. A study in 2003 by Ali and Blunden has shown that taking either the seed extract or its oil will not induce significant toxicity or adverse effects on liver or kidney functions [9]. Therefore, this study proves that $N$. sativa is safe to be used with no significant toxicological or adverse effect.
$N$. sativa is a famous and special plant that has been widely used in different cultures for many centuries [10, 11]. Many studies were interested in this scope such as the seeds of the plant locally known as "Kalonji" which has been used in traditional [12] and alternative medicine for the treatment of a variety of diseases, for example, diarrhea and asthma $[13,14]$. Also, many ancient cultures especially in Asia such as Arabian [15] and African countries used black seed oil in various allergies treatment [16]. It was found that the seeds have been used as flavoring agent in food preparation [17]. These magic seeds have been used for treatment of a variety of sicknesses including parasitic diseases $[18,19]$ and it is used as food preservative as a pharmaceutical powder [20]. Usually developed countries used herbal medicines for the treatment of many diseases such as skin diseases and gastrointestinal diseases such as jaundice, anorexia, dyspepsia, and diabetes $[21,22]$. Other uses include hypertension, intrinsic hemorrhage, paralysis, amenorrhea, anorexia, asthma, cough, rheumatism, bronchitis, headache, fever, influenza, eczema, and assorted health care issues [23-25]. 


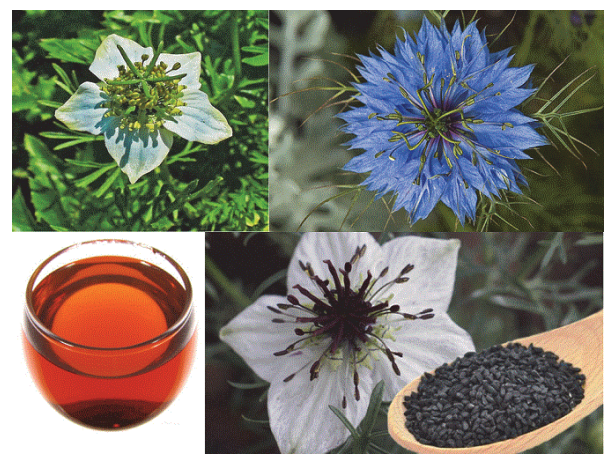

FIGURE 1: Nigella sativa plant, seed, and oil.

The objective of this article is to review the reported cosmeceutical and external application of $N$. sativa. In addition, a review related to the dermatological effects of $N$. sativa seed, its oil, and active ingredients will be conducted.

\section{Nigella sativa External Application}

Nigella sativa has been used for centuries for the treatment of many skin conditions, for dermatological disorder, and in cosmeceutical formulations [26]. For example, it is used for acne vulgaris, burn, wounds, and injury treatment [26-28], anti-inflammatory for different kinds of skin inflammation $[9,29]$, and skin pigmentation effect $[30,31]$.

\section{Antimicrobial Effect}

3.1. Antibacterial. New antimicrobial agents are intensively investigated due to pathogenic bacterial infections and microbial resistance, which have become a major health problem worldwide and this led to an increase in the use of medicinal plants [32]. Therefore, many studies discussed antibacterial efficacy of black seeds. Examples include thymoquinone, which is a part of black seeds oil, which is found to have bactericidal activity against most bacteria that was included in the study (MICs values ranged from 8 to $32 \mu \mathrm{g} / \mathrm{ml}$ ), especially Gram positive cocci types such as (Staphylococcus aureus ATCC 25923 and Staphylococcus epidermidis CIP 106510). For Staphylococcus aureus, clear inhibition of the growth was found by concentration of $300 \mathrm{mg} / \mathrm{ml}$ with distilled water (DW) as control. According to the way that they used for testing, a modified paper disc diffusion method was used. However, there was no effect on E. coli and Enterobacter bacteria [33]. Black seeds have been found effective against $H$. pylori compared with triple therapy [34]. Black seed extract has also been found to have several multidrug resistant clinical bacterial effects [35]. According to those studies, a clear and undeniable antibacterial effect caused by the N. sativa, the inhibition of the bacterial growth, was due to the presence of thymoquinone and melanin. Those findings warrant necessity of further and better investigation of this product.

3.2. Antiviral. A few recent studies were found about the antiviral activity of Nigella sativa extract, for example, a recent
TABLE 1: IC $_{50}$ thymoquinone.

\begin{tabular}{lcc}
\hline & IC value & IC value \\
\hline Candida parapsilosis & $\mathrm{IC}_{50}$ & $2.308 \mu \mathrm{g} / \mathrm{ml}$ \\
Cryptococcus laurentii & $\mathrm{IC}_{50}$ & $9.313 \mu \mathrm{g} / \mathrm{ml}$ \\
\hline
\end{tabular}

TABle 2: $\mathrm{IC}_{50}$ Amphotericin B.

\begin{tabular}{lcc}
\hline & IC value & IC value \\
\hline Candida parapsilosis & $\mathrm{IC}_{50}$ & $57.68 \mu \mathrm{g} / \mathrm{ml}$ \\
Cryptococcus laurentii & $\mathrm{IC}_{50}$ & $15.50 \mu \mathrm{g} / \mathrm{ml}$ \\
\hline
\end{tabular}

study performed in 2013 obtained significant results about the effect of $N$. sativa oil against hepatitis $C$ virus (HCV). Patients with $\mathrm{HCV}$ who cannot receive IFN- $\alpha$ were given $450 \mathrm{mg}$ of $N$. sativa oil in capsular dosage form. After 3 months of treatment 3 times daily, a decrease in overall viral count was noted. An increase in antioxidant activity was also found, indicating a reduction in the hemolysis of red blood cells and platelet. Other findings were observed such as reduction in blood glucose levels and in the lower limb edema. [36]. These findings suggest that $N$. sativa administration will decrease viral load in patients with $\mathrm{HCV}$ and improve oxidative stress, clinical condition, and glycemic control in diabetic patients.

3.3. Antifungal. Nigella sativa oil showed antifungal activity against most pathogenic fungi [37]. Candida tropicalis, Aspergillus flavus, and thymoquinone, which is the main composition of the oil, showed antifungal activity against most fungal strains $[37,38]$. Its antifungal activity compared with antifungal standard drug Amphotericin B. thymoquinone (Table 1) showed more potent activity against fungal strains than Amphotericin B (Table 2). Data is shown in Tables 1 and 2 .

It is also found that thymoquinone has not bad antifungal activity with $\mathrm{IC}_{50}$ against Cryptococcus albidus which is $20.83 \mu \mathrm{g} / \mathrm{ml}$, Candida albicans $23.33 \mu \mathrm{g} / \mathrm{ml}$, Issatchenkia orientalis $25.33 \mu \mathrm{g} / \mathrm{ml}$, and Aspergillus fumigatus $23.40 \mu \mathrm{g} / \mathrm{ml}$ [39].

In another study of $N$. sativa antifungal effect on dermatophyte fungal strains, it was found that the essential oil extract of thymoquinone has an effective antifungal activity on T. mentagrophytes, M. canis, and M. gypseum. Cytotoxicity of $N$. sativa essential oil was included in the study and the results showed that the oil in low concentrations had no significant cytotoxicity in the murine macrophages. However, thymoquinone showed higher cytotoxic effect in comparison with essential oil by the same method of study [40].

In addition, Khosravi et al. (2011) concluded that $C$. cyminum, Z. clinopodioides, and $N$. sativa oils possess antifungal activities to inhibit the growth of $A$. fumigatus and $A$. flavus. The antifungal activity of the oils was evident at the morphological level. Due to the antifungal activity of these oils and their availability as natural volatile products, they might be of use in future studies of antifungal agents [41].

Researchers who studied treatment of fungal infections by using natural products found that $N$. sativa has an 
enhancing antifungal effect $[38,42,43]$. Another research that depended on micro well dilution assay was conducted against three human pathogenic fungal strains Aspergillus flavus, Aspergillus niger, and Candida albicans [6]. Moreover, in 2013 all the extracts of essential $N$. sativa oil showed effective antifungal activity against $C$. albicans, C. tropicalis, and $C$. $k$ rusei at MIC values of $16-64 \mu \mathrm{g} / \mathrm{ml}$ [44].

A study was made on Tunisian N. sativa fixed oil to test its antibacterial and antifungal activity, and the result shows a validation for the folk use of this oil as an antibacterial and antifungal medicine [45]. Therefore, the existence of various chemical compounds in $N$. sativa and their mechanism of action make it a good candidate as an antifungal agent.

3.4. Antiparasitic. In a study conducted in 2014, researchers extracted Nigella sativa seeds by methanolic extraction and tested it on Plasmodium yoelii infection to see its efficacy. It was found that $N$. sativa extract showed $94 \%, P<0.05$, which showed an excellent suppression compared with chloroquine, which is the drug of choice for Plasmodium yoelii infection treatment (methanolic extract of the drug led to $86 \%$ ). The antimalarial activity was because of antioxidant effect from the extract on Plasmodium infected mice. The study was improved to see the antioxidative status in red blood cells, and hepatocytes of infected mice were seen $[46,47]$.

$N$. sativa oil possesses other activities against cestodes and nematodes action [48]. In a recent study, N. sativa oil had an excellent effect in minimizing the total number of Schistosoma mansoni worms in liver and reducing the total number of ova that was found in both liver and intestine [23].

Good results were obtained in a study conducted in 2008. $N$. sativa oil and garlic extract were used to see if there are any antischistosomal and antioxidant activity on normal and Sch. mansoni by using infected mice. It was noted that the infected mice had an improvement in hematological, biochemical, and antioxidant capacity of schistosomiasis mice compared to the infected untreated ones [49].

In 2002, Aboul-Ela used N. sativa oil and thymoquinone to test their efficacy against Sch. mansoni on infected mice. Results obtained in the study showed decrease in chromosomal abnormalities, especially on chromosomes 2 and 6 , and some in chromosomes 13 and 14 when $N$. sativa oil and thymoquinone are used in treatment compared with control group [50].

Another study was conducted to determine the effect of $N$. sativa seeds against some parasites such as Sch. mansoni, miracidia, cercariae, and adult worms. Significant results were achieved as a strong effect against all these parasites and even on their eggs was shown. Also $N$. sativa seeds possess an oxidative activity against adult worms which decrease the activities of some enzymes such as glutathione reductase, antioxidant enzymes, and enzymes of glucose metabolism. When these enzymes are damaged, parasite will be weaker and killed [51]. The presence of antioxidant compounds in $N$. sativa may lead to the collection of free radicals and inactivation of them, which may propose significant marketing advantage, due to consumer preference for antioxidant rich products.

\section{Wound Healing}

Thymoquinone is reported to prevent oxidative injury, act as antioxidant, and prevent membrane lipid peroxidation in tissues; these effects suggested the application of Nigella sativa topically to accelerate wound healing [27]. A study on wound model rates was done to evaluate the wound healing effect of $N$. sativa oil. The results have shown that it increases the wounding process by unknown mechanism compared to silver sulfadiazine, which may be due to anti-inflammatory and immunomodulatory effects. In the future after further studies, we may use $N$. sativa oil instead of silver sulfadiazine to deal with wound [27].

It was found that $N$. sativa oil has good activity on increasing collagen formation and increasing rate of epithelialization. Thus, it has an excellent effect as wound healing and moisturizing effect [52].

Wound healing process was also observed by Abu-AlBasal. He saw that when ether extract of $N$. sativa seed was applied on skin, it improved the healing process by decreasing the total and absolute white blood cells count, reducing tissue damage and decreasing bacterial expansion [53].

A study conducted in 2004 used a monolayer prototype of human gingival fibroblast to test wound healing properties of $N$. sativa extract. Increasing in rate of proliferation was observed and closure activity was seen after using the oil in the study [54]. Thus, according to the results of man of those studies and other researches done, it can be said that N. sativa might be promising in treatment of wound healing.

\section{Anti-Inflammatory}

5.1. Psoriasis. Psoriasis is common skin condition, which is a hyperproliferative, autoimmune skin disorder and can be itchy and painful. An experimental study was undertaken to see the effect of ethanol extract of Nigella sativa seeds in treatment of psoriasis. It was found that $N$. sativa increases the epidermal thickness when case study group is compared to control group that used traditional treatment [55].

Another study was made by Ahmed et al. (2014) to compare asiaticoside and the ethanolic extract of $N$. sativa to see the antipsoriatic effect. $N$. sativa oil was applied in two dosage forms, as an ointment and oral dosage form. They had $\mathrm{IC}_{50}$ value of $23.9 \mu \mathrm{g} / \mathrm{ml}$, which is about the $\mathrm{IC}_{50}$ value for asiaticoside $(20.13 \mu \mathrm{g} / \mathrm{ml})$. In conclusion, $N$. sativa oil had better effect as antiproliferative activity than the compared treatment [56]. It is concluded based on many researches that $N$. sativa has antipsoriatic effect with the best effect obtained with the combination of ointment and the oral dosage form.

5.2. Acne Vulgaris. Acne vulgaris is one of the most prevalent human diseases, which is considered an infectious disease. Many researchers studied the effect of Nigella sativa oil against acne vulgaris. Hadi and Ashor (2010) noticed that using $20 \%$ of $N$. sativa oil extract in lotion formulation has a better efficacy and is less harmful than benzoyl peroxide lotion $5 \%$, which is the basic treatment for mild to meddle stage of acne vulgaris [57]. 
TABLE 3: Some commercial products containing Nigella sativa extract.

\begin{tabular}{lccc}
\hline Name of product & Company & Use & Dosage form \\
\hline Immuno-Viva Core & Immuno-Viva & Natural antioxidant supplement & Capsule and liquid form \\
Al Barakah & Shiffa Home & Increasing immunity and retaining good health & Soft gelatin capsule \\
Blackseed Soap & Hemani & Body soap cleaner & Soap \\
Vatika Black Seed Hair Mask & Vatika Nature & Hair mask & Cream \\
Vatika Naturals Black Seed Enriched & Vatika Nature & Complete hair care, improved shine, texture, and & Oil \\
Hair Oil Complete Hair Care & volume, and reduced hair problem & Shampoo \\
Vatika Black Seed Shampoo & Vatika Nature & Strong and shiny hair & Cream \\
Black Seed Cream & Hemani & Helping in relaxation & Cream \\
Nigella sativa Cream & Bergmeister & Skin cream & \\
\hline
\end{tabular}

A detailed study was conducted on 62 patients. People who have acne and used $N$. sativa lotion as a therapy showed a good decrease in their inflammation and overall number of lesions, the same as benzoyl peroxide. In percentage, more than $50 \%$ of patients who used $N$. sativa lotion had good results, but those using benzoyl peroxide lotions showed up to $50 \%$ fewer lesions. Of the patients who used $N$. sativa lotion, $20 \%$ showed little adverse effects compared to those who used the traditional therapy. However, after patients stopped their scheduled therapy with both lotions, the number of lesions rose 8 weeks after the end of therapy [57].

$N$. sativa seeds have long been used as an external application for different kinds of skin disease. Bhalani and Shah decided to test $N$. sativa oil antibiotic effect compared with standard drug amoxicillin. The results of both treatments were the same in bacterial zone inhibition. In their recent studies they prepared gel dosage form from the oil and Carbopol 940 and tested this formulation as a therapy for acne vulgaris and good results were obtained [58]. Therefore, $N$. sativa is a good candidate in the treatment of inflamed skin which can be caused by infection, irritation, rashes, dermatitis, acne, and psoriasis.

\section{Skin Pigmentation}

6.1. Vitiligo. Nigella sativa oil as shown before is very effective treatment for different kinds of diseases such as vitiligo, which is a hypopigmentation disorder causing considerable psychological morbidity in a large proportion of its sufferers. Some studies have focused on this point.

A research was made on patients suffering from vitiligo lesions. Researchers used fish oil and N. sativa oil as a therapy. Good results were obtained in decrease in the lesions size. It was then decided to include $N$. sativa oil in the basic treatments [31].

A special study was made and noticed that $N$. sativa has the ability to spread melanin within the skin. A possible explanation of the mechanism of this action was that it increased the intensity of melanin by increasing the sensitivity of cholinergic receptors inside the melanopsin, the external part of lizard. That study led them to think about using the active ingredient of $N$. sativa oil, which is thymoquinone, for external problems such as decline in skin pigmentation and vitiligo [30].

\section{Cosmeceutical Application of Nigella sativa}

In 2000, it was mentioned that Nigella sativa seeds could be used in cosmetics because of its aroma components [59]. After that, it was noticed that sun protective factor (SPF) value for $N$. sativa seed oil is more than 2 , so it has some properties against the sun. That means we can use the oil in cosmetics (Table 3) [60].

\section{Conclusion}

In conclusion, this review identified a detailed description on the external application and dermatological application of Nigella sativa with a focus on its cosmeceutical application. Historical evidence showed the relation between $N$. sativa and human health care system from decay to modern times, which is due to its antimicrobial, anti-inflammatory, and antifungal activity with application for variety of diseases like bronchitis, cough, asthma, hypertension, paralysis, amenorrhea, anorexia, and rheumatism. In addition, its low degree of toxicity makes it trusted to be used.

\section{Conflicts of Interest}

The authors declare no conflicts of interest.

\section{Authors' Contributions}

Ahmad Eid conceived, accomplished, and designed the paper. Nagib, Lila, Maher, and Hadeel carried out the literature review and obtained and drafted this paper. All researchers collected the informants and revised, read, and approved the final manuscript.

\section{Acknowledgments}

Sincere thanks are due to all participants in the study.

\section{References}

[1] A. Khalid, Uzair-ur-Rehman, A. Sethi et al., "Antimicrobial activity analysis of extracts of Acacia modesta, Artimisia absinthium, Nigella sativa and Saussurea lappa against gram 
positive and gram negative microorganisms," African Journal of Biotechnology, vol. 10, no. 22, pp. 4574-4580, 2011.

[2] D. Zohary, M. Hopf, and E. Weiss, Domestication of Plants in the Old World: The Origin and Spread of Domesticated Plants in Southwest Asia, Europe, and the Mediterranean Basin, Oxford University Press on Demand, 2012.

[3] M. Tahan and I. Bayram, "Effect of using black cumin (Nigella sativa) and parsley (Petroselinum crispum) in laying quail diets on egg yield, egg quality and hatchability," Archiva zootechnica, vol. 14, no. 4, pp. 39-44, 2011.

[4] A. Ahmad, A. Husain, M. Mujeeb et al., "A review on therapeutic potential of Nigella sativa: a miracle herb," Asian Pacific Journal of Tropical Biomedicine, vol. 3, no. 5, pp. 337-352, 2013.

[5] M. L. Mathur, J. Gaur, R. Sharma et al., "Antidiabetic properties of a spice plant Nigella sativa," Journal of Endocrinology and Metabolism, vol. 1, no. 1, pp. 1-8, 2011.

[6] S. Javed, A. A. Shahid, M. S. Haider et al., "Nutritional, phytochemical potential and pharmacological evaluation of Nigella Sativa (Kalonji) and Trachyspermum Ammi (Ajwain)," Journal of Medicinal Plants Research, vol. 6, no. 5, pp. 768-775, 2012.

[7] H. Jrah Harzallah, B. Kouidhi, G. Flamini, A. Bakhrouf, and T. Mahjoub, "Chemical composition, antimicrobial potential against cariogenic bacteria and cytotoxic activity of Tunisian Nigella sativa essential oil and thymoquinone," Food Chemistry, vol. 129, no. 4, pp. 1469-1474, 2011.

[8] M. A. Dollah, S. Parhizkar, L. A. Latiff, and M. H. B. Hassan, "Toxicity effect of Nigella sativa on the liver function of rats," Advanced Pharmaceutical Bulletin (APB), vol. 3, no. 1, pp. 97102, 2013.

[9] B. H. Ali and G. Blunden, "Pharmacological and toxicological properties of Nigella sativa," Phytotherapy Research, vol. 17, no. 4, pp. 299-305, 2003.

[10] B. Saad, H. Azaizeh, and O. Said, "Tradition and perspectives of Arab herbal medicine: a review," Evidence-Based Complementary and Alternative Medicine, vol. 2, no. 4, pp. 475-479, 2005.

[11] I. N. Mohammed and H. E. Babikir, "Traditional and spiritual medicine among Sudanese children with epilepsy," Sudanese Journal of Paediatrics, vol. 13, pp. 31-37, 2013.

[12] Z. Tasawar, Z. Siraj, N. Ahmad, and M. H. Lashari, “The effects of nigella sativa (Kalonji) on lipid profile in patients with stable coronary artery disease in Multan, Pakistan," Pakistan Journal of Nutrition, vol. 10, no. 2, pp. 162-167, 2011.

[13] A. H. Gilani, N. Aziz, I. M. Khurram, K. S. Chaudhary, and A. Iqbal, "Bronchodilator, spasmolytic and calcium antagonist activities of Nigella sativa seeds (Kalonji): A traditional herbal product with multiple medicinal uses," Journal of the Pakistan Medical Association, vol. 51, no. 3, pp. 115-120, 2001.

[14] A. Benhaddou-Andaloussi, L. Martineau, T. Vuong et al., "The in vivo antidiabetic activity of Nigella sativa is mediated through activation of the AMPK pathway and increased muscle Glut4 content," Evidence-Based Complementary and Alternative Medicine, vol. 2011, Article ID 538671, 9 pages, 2011.

[15] B. A. Bakhotmah and H. A. Alzahrani, "Self-reported use of complementary and alternative medicine (CAM) products in topical treatment of diabetic foot disorders by diabetic patients in Jeddah, Western Saudi Arabia," BMC Research Notes, vol. 3, article no. 254, 2010.

[16] U. Kalus, A. Pruss, J. Bystron et al., "Effect of Nigella sativa (black seed) on subjective feeling in patients with allergic diseases," Phytotherapy Research, vol. 17, no. 10, pp. 1209-1214, 2003.
[17] M. A. Randhawa and M. S. Alghamdi, "Anticancer activity of Nigella sativa (Black Seed) - a review," American Journal of Chinese Medicine, vol. 39, no. 6, pp. 1075-1091, 2011.

[18] H. Abdulelah and B. Zainal-Abidin, "In vivo anti-malarial tests of Nigella sativa (Black Seed) different extracts," American Journal of Pharmacology and Toxicology, vol. 2, no. 2, pp. 4650, 2007.

[19] V. O. Okeola, O. A. Adaramoye, C. M. Nneji, C. O. Falade, E. O. Farombi, and O. G. Ademowo, "Antimalarial and antioxidant activities of methanolic extract of Nigella sativa seeds (black cumin) in mice infected with Plasmodium yoelli nigeriensis," Parasitology Research, vol. 108, no. 6, pp. 1507-1512, 2011.

[20] M. L. Salem, "Immunomodulatory and therapeutic properties of the Nigella sativa L. seed," International Immunopharmacology, vol. 5, no. 13-14, pp. 1749-1770, 2005.

[21] S. Verma and S. P. Singh, "Current and future status of herbal medicines," Veterinary World, vol. 1, no. 11, pp. 347-350, 2008.

[22] E. A. Palombo, "Traditional medicinal plant extracts and natural products with activity against oral bacteria: potential application in the prevention and treatment of oral diseases," Evidence-Based Complementary and Alternative Medicine, vol. 2011, Article ID 680354, 15 pages, 2011.

[23] F. Forouzanfar, B. S. Fazly Bazzaz, and H. Hosseinzadeh, “Black cumin (Nigella sativa) and its constituent (thymoquinone): A review on antimicrobial effects," Iranian Journal of Basic Medical Sciences, vol. 17, no. 12, pp. 929-938, 2014.

[24] Z. Gholamnezhad, R. Keyhanmanesh, and M. H. Boskabady, "Anti-inflammatory, antioxidant, and immunomodulatory aspects of Nigella sativa for its preventive and bronchodilatory effects on obstructive respiratory diseases: A review of basic and clinical evidence," Journal of Functional Foods, vol. 17, pp. 910-927, 2015.

[25] C. Muthu, M. Ayyanar, N. Raja, and S. Ignacimuthu, "Medicinal plants used by traditional healers in Kancheepuram District of Tamil Nadu, India," Journal of Ethnobiology and Ethnomedicine, vol. 2, article 43, 2006.

[26] M. F. Ramadan, "Healthy blends of high linoleic sunflower oil with selected cold pressed oils: Functionality, stability and antioxidative characteristics," Industrial Crops and Products, vol. 43, no. 1, pp. 65-72, 2013.

[27] I. Yaman, A. S. Durmus, S. Ceribasi, and M. Yaman, "Efects of Nigella sativa and silver sulfadiazine on burn wound healing in rats," Veterinarni Medicina, vol. 55, no. 12, pp. 619-624, 2010.

[28] O. Abu-Zinadah, "Using nigella sativa oil to treat and heal chemical induced wound of rabbit skin," Journal of King Abdulaziz University-Science, vol. 21, no. 2, pp. 335-346, 2009.

[29] R. de Cássia da Silveira E Sá, L. N. Andrade, and D. P. de Sousa, "A review on anti-inflammatory activity of monoterpenes," Molecules, vol. 18, no. 1, pp. 1227-1254, 2013.

[30] S. A. Ali and K. V. Meitei, "Nigella sativa seed extract and its bioactive compound thymoquinone: The new melanogens causing hyperpigmentation in the wall lizard melanophores," Journal of Pharmacy and Pharmacology, vol. 63, no. 5, pp. 741746, 2011.

[31] A. Ghorbanibirgani, A. Khalili, and D. Rokhafrooz, "Comparing nigella sativa oil and fish oil in treatment of vitiligo," Iranian Red Crescent Medical Journal, vol. 16, no. 6, 2014.

[32] L. B. Emeka, P. M. Emeka, and T. M. Khan, "Antimicrobial activity of Nigella sativa L. seed oil against multi-drug resistant Staphylococcus aureus isolated from diabetic wounds," Pakistan Journal of Pharmaceutical Sciences, vol. 28, no. 6, pp. 1985-1990, 2015. 
[33] K. Chaieb, B. Kouidhi, H. Jrah, K. Mahdouani, and A. Bakhrouf, "Antibacterial activity of Thymoquinone, an active principle of Nigella sativa and its potency to prevent bacterial biofilm formation," BMC Complementary and Alternative Medicine, vol. 11, article 29, 2011.

[34] E. M. Salem, T. Yar, A. O. Bamosa et al., "Comparative study of Nigella Sativa and triple therapy in eradication of Helicobacter Pylori in patients with non-ulcer dyspepsia," Saudi Journal of Gastroenterology, vol. 16, no. 3, pp. 207-214, 2010.

[35] M. H. Islam, I. Z. Ahmad, and M. T. Salman, "Antibacterial activity of Nigella sativa seed in various germination phases on clinical bacterial strains isolated from human patients," E3 Journal of Biotechnology and Pharmaceutical Research, vol. 4, pp. 8-13, 2013.

[36] E. M. F. Barakat, L. M. El Wakeel, and R. S. Hagag, "Effects of Nigella sativa on outcome of hepatitis C in Egypt," World Journal of Gastroenterology, vol. 19, no. 16, pp. 2529-2536, 2013.

[37] S. Gupta, M. Satishkumar, B. Duraiswamy et al., "Potential herbs and its phytoconstituents against fungal infection: a systematic review," World Journal of Pharmaceutical Research, vol. 1, pp. 120, 2012.

[38] E. A. Rogozhin, Y. I. Oshchepkova, T. I. Odintsova et al., "Novel antifungal defensins from Nigella sativa L. seeds," Plant Physiology and Biochemistry, vol. 49, no. 2, pp. 131-137, 2011.

[39] M. Suthar, P. Patel, T. Shah et al., "In vitro screening of Nigella sativa seeds for antifungal activity," International Research Journal of Pharmaceutical and Applied Sciences, vol. 1, no. 1, pp. 84-91, 2010.

[40] H. Mahmoudvand, A. Sepahvand, S. Jahanbakhsh, B. Ezatpour, and S. A. A. Mousavi, "Evaluation of antifungal activities of the essential oil and various extracts of Nigella sativa and its main component, thymoquinone against pathogenic dermatophyte strains," Journal of Medical Mycology, vol. 24, no. 4, pp. e155e161, 2014.

[41] A. R. Khosravi, M. H. Minooeianhaghighi, H. Shokri, S. A. Emami, S. M. Alavi, and J. Asili, "The potential inhibitory effect of cuminum cyminum, ziziphora clinopodioides and nigella sativa essential oils on the growth of aspergillus fumigatus and aspergillus flavus," Brazilian Journal of Microbiology, vol. 42, no. 1, pp. 216-224, 2011.

[42] A. Bita, A. Rosu, D. Calina et al., "An alternative treatment for Candida infections with Nigella sativa extracts," European Journal of Hospital Pharmacy: Science and Practice, vol. 19, no. 2, pp. 162.2-162, 2012.

[43] A. Asdadi, H. Harhar, S. Gharby et al., "Chemical composition and antifungal activity of Nigella Sativa L. oil seed cultivated in Morocco," International Journal of Pharmaceutical Science Invention, vol. 3, pp. 9-15, 2014.

[44] A. Piras, A. Rosa, B. Marongiu et al., "Chemical composition and in vitro bioactivity of the volatile and fixed oils of Nigella sativa L. extracted by supercritical carbon dioxide," Industrial Crops and Products, vol. 46, pp. 317-323, 2013.

[45] H. J. Harzallah, E. Noumi, K. Bekir et al., "Chemical composition, antibacterial and antifungal properties of Tunisian Nigella sativa fixed oil," African Journal of Microbiology Research, vol. 6, no. 22, pp. 4675-4679, 2012.

[46] S. Tembhurne, S. Feroz, B. More et al., "A review on therapeutic potential of Nigella sativa (kalonji) seeds," Journal of Medicinal Plants Research, vol. 8, no. 3, pp. 167-177, 2014.
[47] G. O. Adam, M. M. Rahman, S.-J. Lee et al., "Hepatoprotective effects of Nigella sativa seed extract against acetaminopheninduced oxidative stress," Asian Pacific Journal of Tropical Medicine, vol. 9, no. 3, pp. 221-227, 2016.

[48] M. R. Mahmoud, H. S. El-Abhar, and S. Saleh, "The effect of Nigella sativa oil against the liver damage induced by Schistosoma mansoni infection in mice," Journal of Ethnopharmacology, vol. 79, no. 1, pp. 1-11, 2002.

[49] N. S. El Shenawy, M. F. M. Soliman, and S. I. Reyad, "The effect of antioxidant properties of aqueous garlic extract and Nigella sativa as anti-schistosomiasis agents in mice," Revista do Instituto de Medicina Tropical de São Paulo, vol. 50, no. 1, pp. 2936, 2008.

[50] E. I. Aboul-Ela, "Cytogenetic studies on Nigella sativa seeds extract and thymoquinone on mouse cells infected with schistosomiasis using karyotyping," Mutation Research - Genetic Toxicology and Environmental Mutagenesis, vol. 516, no. 1-2, pp. 11-17, 2002.

[51] A. M. Mohamed, N. M. Metwally, and S. S. Mahmoud, "Sativa seeds against Schistosoma mansoni different stages," Memórias do Instituto Oswaldo Cruz, vol. 100, no. 2, pp. 205-211, 2005.

[52] P. Sarkhail, H. Esmaily, A. Baghaei et al., "Burn healing potential of Nigella sativa seed oil in rats," International Journal of Pharmaceutical Sciences and Research, vol. 2, no. 1, pp. 34-40, 2011.

[53] M. A. Abu-Al-Basal, "Influence of nigella sativa fixed oil on some blood parameters and histopathology of skin in staphylococcal-infected BalB/C mice," Pakistan Journal of Biological Sciences, vol. 14, no. 23, pp. 1038-1046, 2011.

[54] M. R. Ab Rahman, F. Abdul Razak, and M. Mohd Bakri, "Evaluation of wound closure activity of nigella sativa, melastoma malabathricum, pluchea indica, and piper sarmentosum extracts on scratched monolayer of human gingival fibroblasts," Evidence-Based Complementary and Alternative Medicine, vol. 2014, Article ID 190342, 9 pages, 2014.

[55] L. P. Dwarampudi, D. Palaniswamy, M. Nithyanantham, and P. S. Raghu, "Antipsoriatic activity and cytotoxicity of ethanolic extract of Nigella sativa seeds," Pharmacognosy Magazine, vol. 8, no. 32, pp. 268-272, 2012.

[56] H. Ahmed Jawad, Y. Ibraheem Azhar, and I. Al-Hamdi Khalil, "Evaluation of efficacy, safety and antioxidant effect of Nigella sativa in patients with psoriasis: a randomized clinical trial," Journal of Clinical and Experimental Investigations, vol. 5, no. 2, pp. 186-193, 2014.

[57] N. A. Hadi and A. W. Ashor, "Nigella sativa oil lotion $20 \%$ vs. benzoyl peroxide lotion $5 \%$ in the treatment of mild to moderate acne vulgaris," Iraqi Postgraduate Medical Journal, vol. 9, no. 4, pp. 371-376, 2010.

[58] U. Bhalani and K. Shah, "Preparation and evaluation of topical gel of Nigella sativa (KALONJI)," International Journal of Research and Development in Pharmacy \& Life Sciences, vol. 4, no. 4, pp. 1669-1672, 2015.

[59] M. Burits and F. Bucar, "Antioxidant activity of Nigella sativa essential oil," Phytotherapy Research, vol. 14, no. 5, pp. 323-328, 2000.

[60] S. Kale, P. Ghoge, A. Ansari, A. Waje, and A. Sonawane, "Formulation and in-vitro determination of sun protection factor of Nigella sativa Linn. seed oil sunscreen cream," International Journal of PharmTech Research, vol. 2, no. 4, pp. 2194-2197, 2010. 


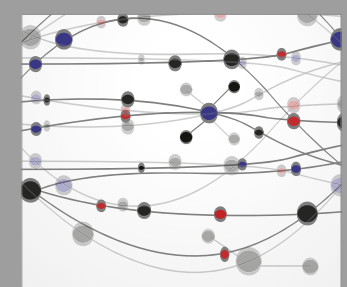

The Scientific World Journal
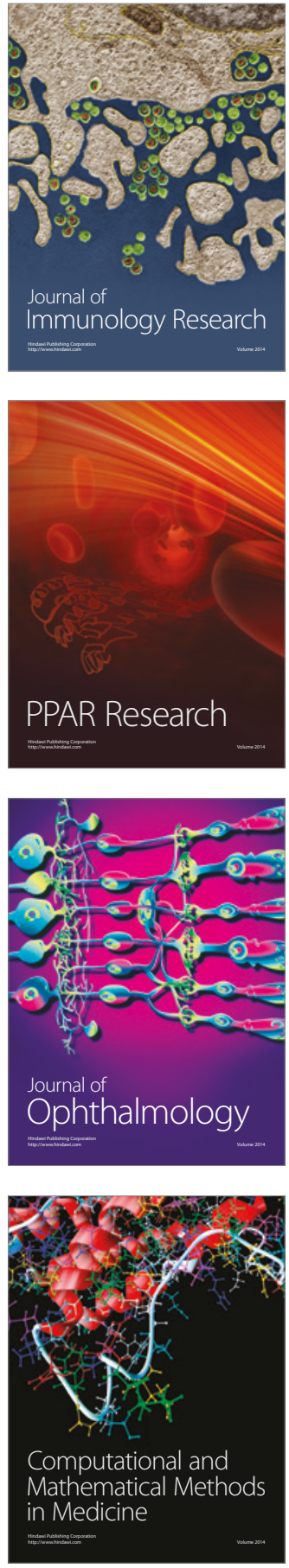

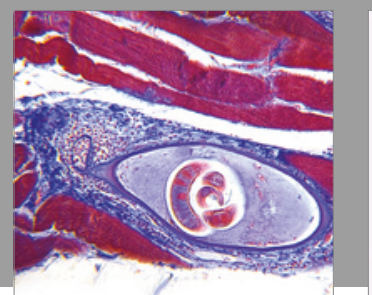

Gastroenterology Research and Practice
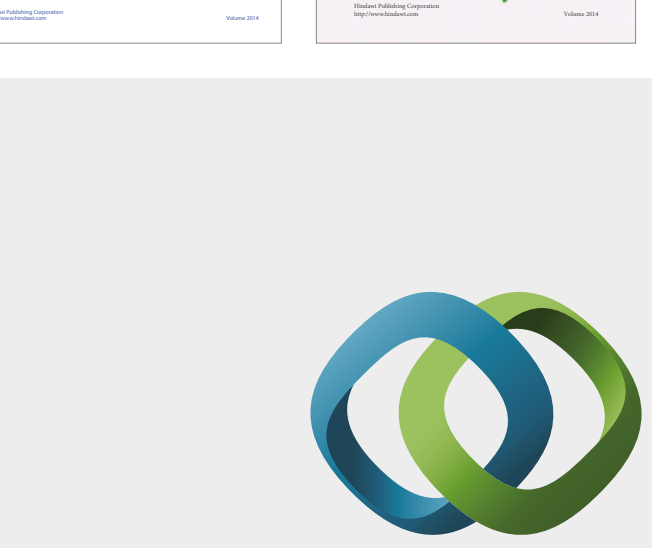

\section{Hindawi}

Submit your manuscripts at

https://www.hindawi.com
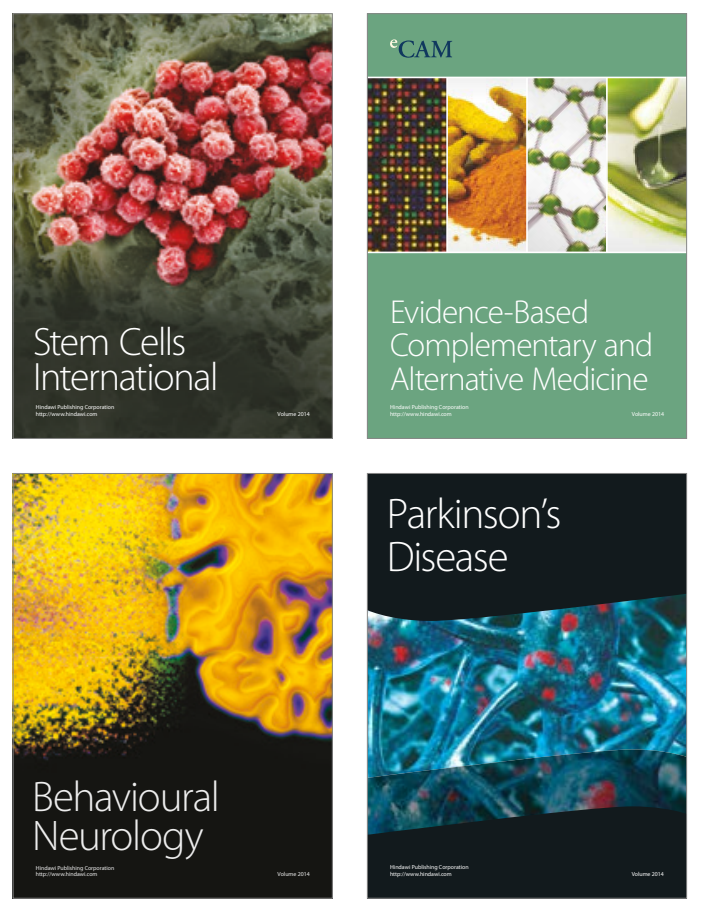
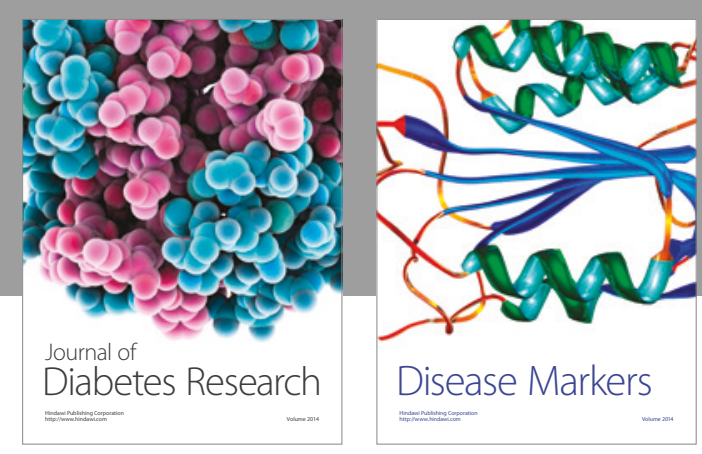

Disease Markers
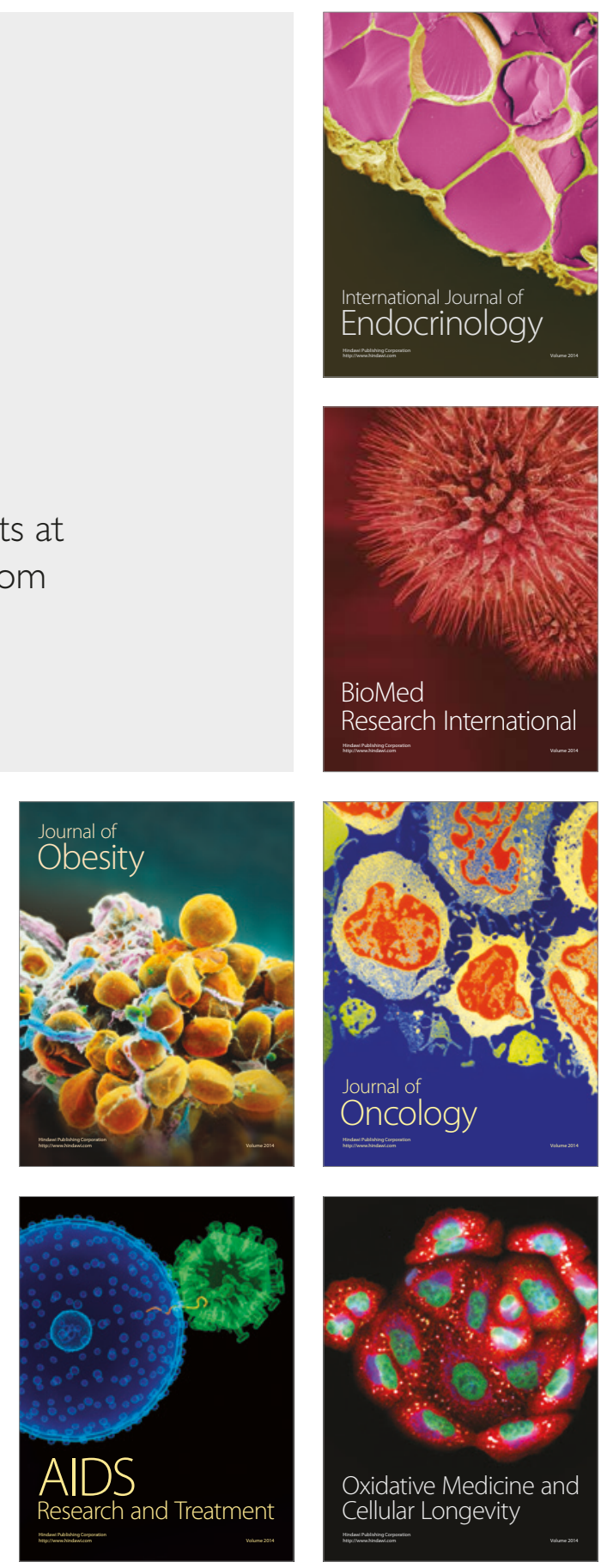